\title{
Chapter 6 \\ Ethnocinematographic Theory. How to Develop Migration Theory Through Ethnographic Filmmaking
}

\author{
Sanderien Verstappen, in conversation with Isabelle Makay, and \\ Mario Rutten
}

\subsection{Introduction}

While teaching ethnographic filmmaking, I have often sat alongside students in the editing room. I watched them going through their materials, playing video after video, wondering how to start editing, intuitively starting to move files around, and soon enough, getting into a flow. In the process, they analysed their materials, discussed and reviewed their analysis, and gradually developed an argument for their final film montage and accompanying paper. I have come to think of this process as "theorizing-through-film", and of the outcomes as "ethnocinematographic theory".

Some students register for visual anthropology classes because they feel they are weak in theory and hope that they will do better as filmmakers. They believe that theory is done through writing, and that filmmaking is something else. Thus, they come to class expecting to learn about camera work, sound recording, and editing, but not expecting to do much thinking, analysis, or writing. As a visual anthropology lecturer, my task is to debunk the myth of theory as a purely textual endeavour. I teach that writing and filmmaking are merely other ways of arriving at theory, and that an alternation between filming and writing can enhance both the writing and the editing process. Theorizing-through-film is a skill that all students can learn, and that university lecturers can support by creating intellectually engaging support structures.

Sanderien Verstappen, in conversation with Isabelle Makay, and Mario Rutten

S. Verstappen $(\square)$

University of Vienna, Vienna, Austria

e-mail: sanderien.verstappen@univie.ac.at 
How can filmmaking produce theory? In this chapter I use the example of migration theory to answer this question. First, filmmaking offers possibilities for expressing migration theory. In the film Living like a common man (2011), a translocal montage of juxtaposition enables the viewer to access a transnational social field, from the perspective of people who move within it, and conveys a visual argument about how migration experiences are shaped by social-economic conditions on different sides of the ocean. Second, ethnographic film offers a possibility for developing new ideas, and for doing so collaboratively. Our film Living like a common man was shaped by a team of three directors (myself, Mario Rutten, and Isabelle Makay), and the relations we established in our film crew generated a challenging mode of thinking-together. If ethnographic theorizing is often perceived to be a solitary process, the practices of filmmaking may invite and support more collaborative approaches of ethno(cinemato)graphic theorizing.

Besides illustrating how film can express as well as generate migration theory, this paper intervenes in a long-term discussion in visual anthropology about the relations between film and text, and ethnography and theory. In their efforts to defend ethnographic filmmaking as a mode of scholarship within a "discipline of words" (Mead, 2003), visual anthropologists have argued that film is an alternative venue for knowledge creation. These discussions have pointed towards the unique qualities of filmmaking as a way of knowing (MacDougall, 2006) and thus suggest that the two modalities of knowledge creation (text and film) are ontologically different. Recent conversations about the role of words within films problematize this distinction (van de Port, 2018); I extrapolate this discussion here to consider written articles and cinematographic outputs as interrelated rather than contrasting forms of research and publication. In my experience, text and film are merely supplementary modes of thinking through a topic, and I have always worked precisely by moving across these two genres. I thus propose a different model of interrelation between the two instances of knowledge creation, which is hybrid and non-hierarchical. I have developed this approach in conversations with my colleagues Mario Rutten and Isabelle Makay through collaborative ethnocinematographic research, and I currently develop it further with students in visual anthropology courses.

\subsection{Where Is the Theory in Ethnographic Film?}

Recurrent discussions in visual anthropology have critically considered the role of theory in the field, for example in a fierce polemic around "where is the theory in visual anthropology?" in the journal Visual Anthropology (Hockings et al., 2014). It has been argued that ethnographic film is "full of rich indicators of behavioural themes" but "poor at generalising" (Hockings, 2014, p. 440). Some scholars do not consider this a problem: for them, theory formation does not need to be central to the endeavour of ethnographic filmmaking, as the special capacity of film is rather in its invitation to "enter into a flow of events" and to establish a shared experience between the viewers, the filmmaker, and the film protagonists (Carta, 2014, 
pp. 452-454). This line of argumentation highlights the use of film as a mode of communication about "being", not only "meaning" (MacDougall, 2006). Observational Cinema, in particular, is associated with an open-ended style of continuity editing whereby the constructed character of the film is made almost invisible through the usage of long uninterrupted takes and almost seamless cuts, to offer the audience an experience of "being there" (Kiener, 2008, p. 407). The scholarly contribution of such open-ended films is understood as their availability in teaching and conferences, where they allow for multiple interpretations and discussions (e.g. in Ruby, 2000, pp. 118-121). The renowned ethnographic filmmakers Timothy Asch, John Marshall, and David MacDougall, for example, thought that the imposition of an interpretative harness would render a film less valuable because, as Asch experienced, theoretical fashions come and go, turning from "explanation" into "joke" (ibid, p. 129), while film remains available in the archive for reinterpretation. They thus found open-ended films most valuable for theory formation in the long term.

Other voices in this discussion however express dissatisfaction about the perceived lack of theoretical ambition on behalf of ethnographic filmmakers who prioritize the methodological and the descriptive over the theoretical and the analytic (Ruby, 2014, pp. 442-444). Indeed, many ethnographic filmmakers have perceived their practices as a project of theory - to illustrate existing theory, or even as a distinct mode of theory formation. ${ }^{1}$ This position has been most prominently taken up in discussions about "transcultural montage" (Suhr \& Willerslev, 2013), which show that films can go beyond observation and description, and indeed "show the invisible" (Suhr \& Willerslev, 2012). This approach favours constructive and assertive editing styles and finds inspiration in essayistic or experimental film genres rather than Observational Cinema.

These debates on theory and ethnographic film have been highly polemic, one side striving towards open-ended observation, the other conceptualising of filmmaking as a constructive endeavour of theory formation. Sometimes, the distinction is indicated by referring to the more open-ended films as "ethnographic films" and to the more argumentative films as "anthropological film". I argue, here, however, that these positions are not mutually exclusive; moreover, that the distinction between "ethnographic" (descriptive) and "anthropological" (theoretical) films is misleading. Is ethnography merely a practice of conveying observed situations? Or is it also an act of interpreting, analysing, and conceptualising, thus of theorizing? It is both: in ethnography (both written and cinematographic), description and theory are united. This unity is precisely the aim of the endeavour, when ethnography is perceived as a unique contribution to theory formation through fieldwork, a

\footnotetext{
${ }^{1}$ For example, at the RAI Film Festival Conference 2019, a panel on "Transforming theory in and through film", chaired by Mattijs van de Port (University of Amsterdam) and Janine Prins (Leiden University) on March 29, 2019, explored examples of theorizing through film. Website https:// raifilm.org.uk/programme-2019/transforming-theory-in-and-through-film-part-i/, accessed
} February 23, 2019. 
process of "grounded theory" (Beuving and de Vries, 2015). ${ }^{2}$ Rather than taking concepts from existing theories to explain fieldwork situations, in a deductive manner, ethnographic fieldwork enables researchers to develop new concepts that are more suitable to explain the phenomenon under study, in an inductive manner. The value of such an approach has for example been highlighted in the journal $H A U$ : Journal of Ethnographic Theory, which has aspired to "return anthropology to its original and distinctive conceptual wealth - to critical concepts we bring from the field" (Da Col and Graeber, 2011, pp. vi-Xxxv). Ethnography is positioned here not as mere description of the minute of everyday life, but as central to theory formation.

In addition to this notion of "ethnographic theory", I propose a view of ethnographic filmmaking as an endeavour of "ethnocinematographic theory". Instead of either devaluing theory or devaluing observation, I work here to explain precisely how ethnographic film can support theory formation. My argument is as follows. Theories are efforts to explain or interpret phenomena. Methodology handbooks describe ethnographic inquiry as particularly useful in developing middle-range theories - to explain a distinct or limited phenomenon (Bryman, 2016). I argue that ethnographic film, like all ethnography, can be a highly useful site for middle-range theorising - for example, in migration studies.

I illustrate this argument through the making of the film Living like a common man (Verstappen, Rutten, \& Makay, 2011), which illuminates the migration experiences of Indian youth in London. The film follows (through observational cinema) a group of young migrants from India in London, and argues (through translocal montage) that their migration is an ambivalent experience of simultaneous downward and upward social mobility. This argument of ambivalence was conveyed cinematographically in the film and made explicit later in a written journal article, "Middling migration" (Rutten and Verstappen, 2014).

\subsection{A Middle-Range Theory: Middling Migration}

Why do young people from middle class families in provincial India go to London? How do they experience this move and what do they get out of it? These exploratory questions were the starting point for a multi-sited research project among young Indian (Gujarati Hindu) migrants in London and their parents in Gujarat, which

\footnotetext{
${ }^{2}$ Grounded theory refers to a process of theory formation in the qualitative social sciences. It is an inductive process that aims to construct abstract categories from observable phenomena. Research that aims to develop grounded theory is different from journalistic and artistic forms of research in that data collection is guided by the ambition to develop theory (an abstract understanding of society), and it is different from grand theory in that the social abstractions it develops are directly related to observable phenomena (Beuving \& De Vries, 2015, p. 48). For original discussions, see Glaser and Strauss (1967), also Miller and Fredericks (1999).

${ }^{3}$ Critical voices have indicated that the potential of this idea of ethnographic theory has not (yet) been fully realized by the $H A U$ journal (e.g. Mahi Tahi, 2018).
} 
documented the unsettling and often temporary migration experiences of provincial middle-class youth who increasingly participate in international education and high-skilled labour migration. Existing theories of student and labour mobility were insufficient to analyse their experiences. Instead, we developed a framework of "middling migration". We argued that the "middling" (intermediate) social position of these migrants produces an ambivalent and contradictory experience of simultaneous upward and downward social class mobility.

This argument was forwarded visually in the film "Living like a common man" (2011) through a transnational montage of juxtaposition, and later substantiated in the article "Middling migration" (2014) with further descriptions and analysis. The film can be watched as a stand-alone visual argument, and was screened as such on the Indian television channel $N D T V,{ }^{4}$ at film festivals, conferences, and public events. ${ }^{5}$ It can also be viewed alongside the article, and has been used in that way as teaching material in university courses on migration and globalisation. ${ }^{6}$ Taken together, the film and article demonstrate how we employed filmmaking in this collaborative research project as a tool of exploration, analysis, and synthesis.

The project started with an observation. In 2007, two brothers decided to move from central Gujarat to London on temporary visa. Mario Rutten, an anthropology professor, had known these two young men since they were children because he had been a regular visitor of their family during long-term fieldwork in Gujarat since 1983. He was surprised by their move. Although central Gujarat is one of the regions in India with a relatively high proportion of international migrants, especially in the UK, this particular family had always claimed not to have migration aspirations. In contrast to the settled Gujarati community in London, who had left India long ago on the basis of prior links to British colonial East Africa and ensuing family connections, the departure of these two young men from middle-class backgrounds without prior family ties to the UK seemed to constitute a different form of mobility. Instead of relying on marriage or family networks, they had sought the help of a visa consultancy agent to organise their migration and moved on the basis of student or temporary work visa. ${ }^{7}$

\footnotetext{
${ }^{4}$ NDTV 24×7 (New Delhi Television): 21 April 2012 (3 pm) and 22 April 2012 (11 pm), 40-minute version.

${ }^{5}$ The film was screened at 17 international film festivals, 16 public events, and in more than 40 academic and educational settings. For updated information about screenings, see the "Living Like a Common Man" website: https://sites.google.com/view/living-like-a-common-man/ festivals-screenings

${ }^{6}$ The film has been acquired as study material for university courses at the University of Amsterdam, Vrije Universiteit, Leiden University, Utrecht University, Radboud University Nijmegen, Ashoka University, Bar Ilan University, the Institute des Hautes Etudes de Management in Morocco, Loughborough University, Göttingen University, Haverford College.

${ }^{7}$ The UK was the most popular migration destination at the time of the film project (2007-2011), with Australia as an important additional destination. In 2011-2012, changing migration and deportation policies in the UK were already causing visa agents in central Gujarat to look for other destinations in Europe and Australia, in the years thereafter Canada emerged as a new site of aspiration.
} 
The migration of the two brothers became the starting point of a research project among young Gujarati migrants in London. The main research method was the making of an ethnographic film. The film portrayed the everyday life in one house in east London, where the brothers lived. The residents of this house were 12 young migrants from central Gujarat, and the film focussed on a group of five residents who often spent time together as friends (including the two brothers). Furthermore, the research included interviews with 26 young migrants from central Gujarat in London, ranging in age between 21 and 32 years. Most of these interlocutors were employed in London in manual jobs as waiters, shop attendants, home helpers, babysitters, or as lower office workers, despite the fact that they had acquired a Ba. degree in Gujarat prior to arrival. Most were from the Hindu caste of Patels (19), while 3 were Brahmins, and 4 belonged to the category of "OBC" ("other backward castes") in India.

Their experiences raised unanswered questions about two themes that had not received much attention in migration literature yet. First, most studies at the time were concerned with either the integration of migrants in their countries of settlement or the transnational networks settled migrants establish to maintain connection with their countries of origin, whereas temporary forms of mobility did not fit in with these categories. Second, with regards to class, most migration studies dealt with either the lower or upper end of migration, focussing on unskilled and semiskilled labour from the Global South to the Global North (Smith \& Guarnizo, 1998), or on the movement of elites and highly skilled workers to the Global North or within the within the Global North (Xiang, 2007; Upadhya, 2008). Young Indians on temporary student or high-skilled visa did not fall in either of these categories. They came from middle-ranking families of landowning farmers and small-scale entrepreneurs in Gujarat, often belonging to the dominant social and caste groups in their villages, however they could also not be considered "elite", as their families lived in rural regions and lacked access to India's top-tier educational institutes and professional labour markets. The project intervened by developing an ethnographic description as well as an empirically grounded middle-range theory to understand the migration experiences of this new cohort of migrants.

To conceptualise "middling migration", we looked for inspiration in other studies of mobility experiences, in particular, the temporary study and work mobility of young people in the Global North (e.g. backpackers), who also occupy middling social or economic positions (Conradson \& Latham, 2005a). For example, descriptions of youth from middle-class backgrounds in New Zealand living temporary in the UK reveal similar experiences. They, too, are highly educated or have a highskilled work visa but rarely manage to find high-skilled work and thus do manual work during their stay in the UK. As youth, they also share a sense of coming of age: an experience of freedom, friendship, and breaking away from social norms, and a possibility of "growing up", becoming independent from the family through a phase of (temporary) hardship (Conradson \& Latham, 2005b). However, in contrast to backpackers, the Gujarati youth we filmed in London were also driven by economic concerns, hoping to improve their position at home by earning money, 
sending gifts and remittances, or investing in land or business in India (for comparable case studies, see Ahmad, 2011; Ali, 2007; Baas, 2010).

Their experiences are "middling" in terms of their class position, their coming of age, their continuously shifting aspirations, and their experiences of simultaneous downward and upward mobility. Their downward mobility was expressed in the following quote by one of the film protagonists (Vishal), which became the title of the film: “... in India I live like a prince. I don't need to do anything, everything is ready for me. (...) But in London I am living like a common man." Living with many other young Indians in the same house in London, sleeping on bunk beds, struggling financially to make ends meet, doing manual work in the service or care sector (which they would not do at home), and having to do one's own household chores (which would be taken care of by their mothers or servants at home) were challenging experiences, particularly for young men from higher and middle-caste backgrounds, who felt that they "become smaller by doing all these things".

Nevertheless, these young people and their family members in Gujarat simultaneously experienced a social ascent, a process of upward mobility. When the young migrants return to India for home visits, they portray an image of success despite their hardship in London. While their relatives and friends in India show awareness of the poor living conditions of the migrants, and sometimes gently ridicule them, they also envy the financial and personal independence of those living abroad: the ability to gain work experience beyond the family business, to make one's own money, and to take one's own decisions with regards to work, spending, friendship, and even love. Such independence is also seen as demarcating a transition from child to adulthood, a rite de passage. Overall, the migration experience is an ambivalent one of both upward and downward social mobility. This was conveyed in the film montage by juxtaposing the experiences of young migrants in India and London (Fig. 6.1).

The accompanying article "Middling migration" made our argument of simultaneous upward and downward mobility explicit and embedded it in a broader analysis of the social, economic and historical context. Its contribution to migration scholarship was its fresh insight into the migration of young people from middle class backgrounds from the Global South to the Global North. Others have argued that the convergence of internationalisation of higher education with increasing restrictions on family and labour migration has led to an increase of student migration flows from middle class backgrounds (Luthra \& Platt, 2016), and that the migration of young people on student or other temporary "high-skilled labour" visa does not fit in with existing frameworks of "high-skilled migrants", "international students", "working holiday-makers" or "labour migrants" (Bielewska, 2018, Jankowski, 2018, Helleiner, 2017). The notion of "middling migration" was found useful in other qualitative case studies of young Indian migrants to think through the specificity of their experiences of liminality, e.g. in the Netherlands (Kirk, Bal, \& Janssen, 2017) and Poland (Jaskulowski, 2018), and has been used in a quantitative effort to identify and measure the distinctive class backgrounds of international students coming to Europe (Luthra \& Platt, 2016). 

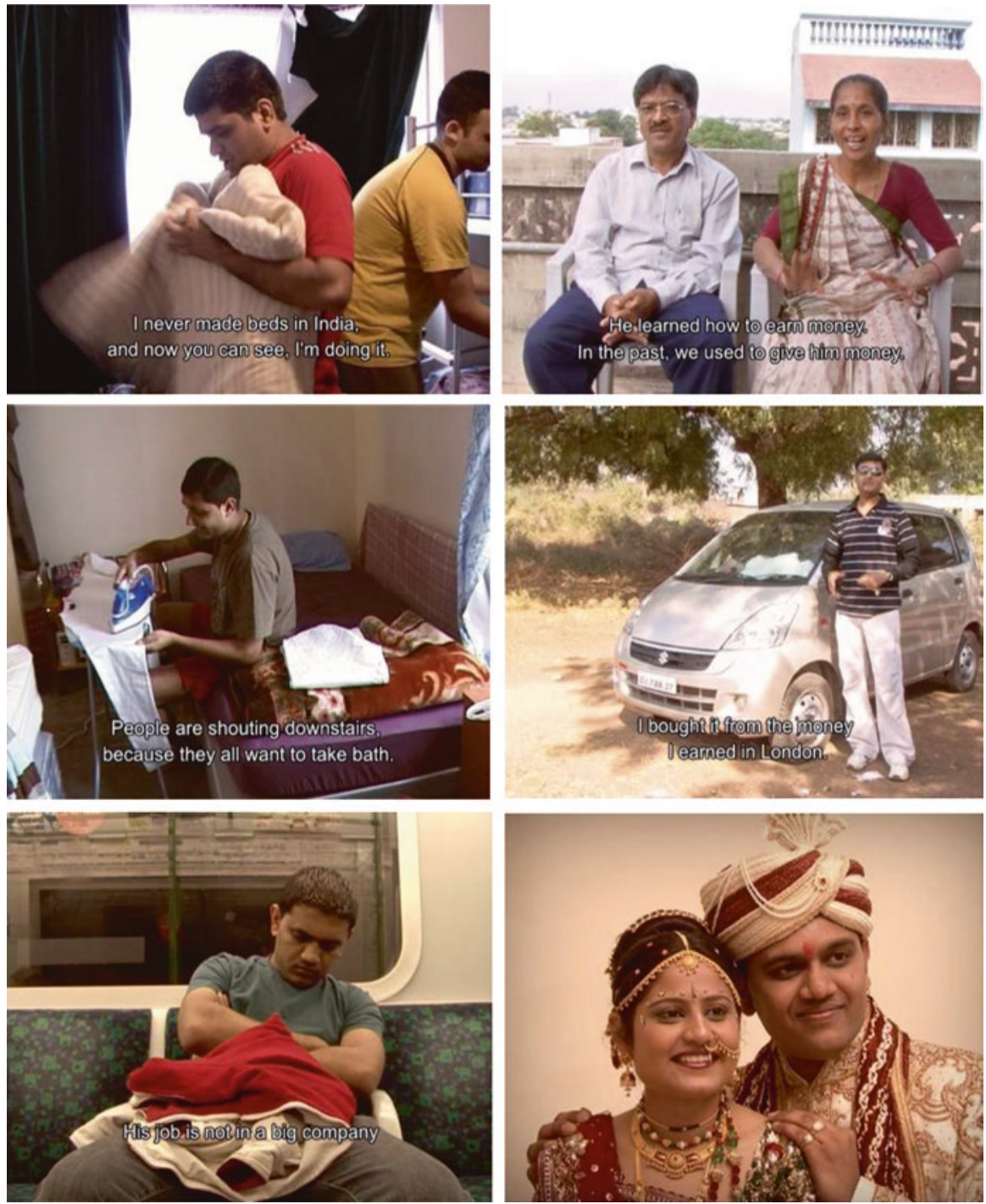

Fig. 6.1 Film stills Living like a common man, directed by Sanderien Verstappen, Mario Rutten and Isabele Makay. Left: experiences of downward mobility, right: experiences of upward mobility 


\subsection{How We Developed Ideas Collaboratively}

We arrived at this analysis through a film project in one house in East London, which was inhabited by 12 recently arrived young people from central Gujarat. During a period of almost a year we made regular visits to the house, using an observational style of filmmaking to follow their daily routines. We filmed the youth while going to work, spending leisure time, making new friends, and calling loved ones in India on the phone. In India, we followed them during their home visits and recorded interviews with their parents. Further insights were gathered when we screened the film with various audiences (Rutten \& Verstappen, 2015) - including the interlocutors, who first commented on the edited film as part of a consent procedure $^{8}$ before the film was released to wider audiences.

Living like a common man was recorded during eight field trips to London and a two-week fieldtrip to India, from May 2008 to March 2009. We recorded more than $70 \mathrm{~h}$ of footage, $47 \mathrm{~h}$ in London and $23 \mathrm{~h}$ in India, and edited this material into a film of $65 \mathrm{~min}$. Preparation started in 2007 with the migration of the two brothers (mentioned above). Having known Rutten since they were born, they approached him at the time as a familiar contact in Europe ("uncle"). In May 2008, Rutten spent a weekend with them in London and met the other residents of the house where they lived. During a second trip, he introduced Verstappen and the camera, and discussed the idea of potentially making a film. They responded positively to the idea. During a third field trip, we introduced Makay as the main cameraperson. In the following months, she would be alternately accompanied by Rutten, Verstappen, or both. During the editing phases, Makay and Verstappen edited the film ${ }^{9}$ while Rutten simultaneously wrote short stories about the main characters. ${ }^{10}$ Throughout the process we worked together as a team of three directors.

This team of three directors was a diverse one. Rutten was seen as an uncle by the two brothers, Makay and Verstappen were new to the family and to Gujarat. Rutten was a professor in anthropology, Makay and Verstappen had recently

\footnotetext{
${ }^{8}$ Consent for the publication of the film has been reached with the youth featuring in the film during a set of personal meetings in London. They saw the film first before it was released. Their varied considerations were then taken into account in the distribution process, which aimed to strike a balance between the desire to reach an audience and the protection of interlocutors from possible risks. For example, rather than relasing the film online we rather opted for a layered moderation of the distribution process with theatre and educational screenings for designated audiences. For the television broadcast on $N D T V$ we deleted sensitive scenes, thus shortening the film to approximately 40 minutes (the original duration of the film is $65 \mathrm{~min}$ ).

${ }^{9}$ The editing process took place between May 2009 and December 2010. The editing was done by Verstappen and Makay at alternate periods during vacation periods. It was partly delayed because of a delay in the translation process. Following post-production (colour and sound correction), a first public screening took place at the East End Film Festival in London on 1st May 2011, and the Dutch premiere took place at Beeld voor Beeld filmfestival in Amsterdam on 9 June 2011.

${ }^{10}$ The stories were published in CUL, a magazine for students of the University of Amsterdam (Rutten, 2008-2009), bundled in a booklet that went along with the DVD of the film, and eventually published in a book (Rutten, 2015).
} 
completed their Master studies. Rutten was male, Makay and Verstappen female. Rutten was a writing anthropologist, Makay primarily a filming anthropologist, and Verstappen navigated between them as an anthropologist who moves across both mediums. Despite our differences, we agreed that our relationship would be egalitarian - a team of equal directors, each with an influential role in the preparation, shooting, and editing of the film, and each with veto power. This non-hierarchical collaboration agreement ran contrary to common practices in documentary filmmaking, in which tasks are usually clearly delineated, with the camera and sound person following the instructions of the director. As a result, several colleagues warned us for problems, and one experienced filmmaker said we were setting ourselves up for failure. However, our egalitarianism stemmed from necessity. All three of us had full-time jobs and worked on the project in weekends and holidays, with very limited project funding. None of us was interested in contributing our labour to the project if others would dictate the conditions of participation. Moreover, we knew that in order to make a great film we needed more than our individual contributions - we needed the skills and knowledge of each of us. We were simply going to have to figure it out as a team.

Besides collaborating with each other, we collaborated with the research participants - the two brothers, and their friends and co-residents. For the two brothers, the expectation of the research project was shaped by their trust relation with Rutten and their earlier experiences with his written publications, which had included photos and stories of their family. An additional reason they were happy with the presence of the film crew was the opportunity to speak English. Living in an Asian neighbourhood in a house with only Gujarati's, and working in Gujarati-owned companies, they had not yet had many opportunities to develop their spoken English during their stay in the UK. When asked about their intended audience, the youth said they hoped their peers in India would see the film so that they would know what life in London is like - that the streets in London are not paved with gold. Initially, they took our visits as an occasion to make tourist trips to central London, to the Thames, the Trafalgar square, Victoria Park, and Greenwhich - in these initial shootings they projected an image of success, fun, and friendship. In the later shootings they gradually showed more of their everyday life, including the difficult and tiresome moments, which then also allowed them to demonstrate their success in enduring and overcoming hardship.

Recording and editing Living like a common man was not a matter of searching for the best way to get a predetermined story across. On the contrary, the filmmaking was an explorative process, which generated new insights into what was going on in the lives of the migrants. This open-ended nature of the research was somewhat complicated because of the different perspectives of the directors. Rutten, due to his prior knowledge, inquired in-depth about the migrants' relations with their families and their family histories; Verstappen, due to her concentration on the filmmaking, prioritized currently observable situations in the UK; and Makay, as the main camera person recording the practicalities of living in the congested space of the house, brought to light concerns about hygiene and food. From these different perspectives resulted different ideas about the film, which questions should be 
asked, and how to divide our time in the field. As Tsing notes, "...creative authorship in collaboration is hard work. (...) it requires a labor of emotional intimacy, entailing close hours and long years of negotiation and great care over procedural matters" (Choy, Faier, Hathaway, Inoue, Satsuka, Tsing, 2009, pp. 380-381).

Indeed, our project generated many lengthy discussions. As the recording and editing was a collective endeavour, discussions were an inseparable part of the research. During the recording phase, we talked about our observations after each visit to the house, considered possible interpretations and explanations, and agreed on a plan for the next shooting. During the editing process, we discussed what themes seemed important and if and how these themes could be used to construct a narrative. In times of disagreement, the three makers probed each other to explicate ideas and interpretations, to question each other's presuppositions. We learnt to plan our meetings over weekends so that we had two days, one day for orientation and a second day to confront and further discuss challenges, so that disagreements could be dealt with in intervals, returning to it after everyone had given it some thought. The outcome of such a session would be a plan for the next phase of the editing process.

Ethnographic films have often been collaborations between a writing anthropologist and a filmmaker (Postma \& Crawford, 2006, p. 3). Such collaborations were the preferred method of Timothy Asch, who worked with authors like James J. Fox and E. D. Lewis to make films in Indonesia (Lewis, 2004; Ruby, 1995) and with Napoleon Chagnon to make a series of films in the Amazon. In some cases, the writing anthropologist merely provides access while the filmmaker (or filming anthropologist) develops the film independently; in other instances, the writing anthropologist has an influential role during the shooting and editing process (Barbash \& Taylor, 1997, pp. 74-88; Levin \& Cruz, 2008). With the advent of lightweight cameras and reduced costs for editing sets it became easier to make films as an individual: this was the preferred method of MacDougall (2008, p. 20), who wrote that the relationship with his informants is more intimate when he is filming alone; and of Mead (2003), who argued that "...the best work is done when filmmaker and ethnographer are combined in the same person". Nevertheless, even today, many filmmakers prefer to work in collaborative constellations to incorporate different forms of expertise. Our project illustrates that collaborative filmmaking is not only possible, it can also be generative in shaping new ideas and interpretations throughout the process. While the diversity of our interests created practical challenges, it also challenged us to incorporate different elements in the analysis and to carefully consider and cross-examine our observations and interpretations.

\subsection{How We Developed an Argument Through Montage}

In grounded theory formation, qualitative analysis consists of three steps: (a) careful exploration of data; (b) reducing the number of themes by distinguishing important ones from minor ones; and (c) structuring themes in relation to each other (Boeije, 
2005, pp. 85-119). Our editing followed these steps, starting with reviewing the material and delineating themes, then selecting themes through discussion of the footage, and finally constructing a narrative film. While watching the film material, when we saw certain themes emerging as powerful from the material, we discussed and further developed these in the editing process. We followed a twofold editing process, which we called: "from large to small" and "from small to large".

When editing "from large to small", we categorised the footage - by creating separate folders and timelines for each of the protagonists, and for footage of the house in which they lived. An example of a timeline that was generated in this phase (by Makay), of the film character Sohang, was approximately three hours and contained elements of all the scenes we had recorded with him. This timeline was viewed by the three directors together during a meeting. During the discussion that followed we identified strong material, which we found striking or significant, and singled out key scenes. For example, Sohang's decision to move back to India before his visa expired turned out particularly moving, not only due to the long interview in which he explained his motivations but also due to the footage shot after the interview, in which Sohang opened his suitcases to show his passport and ticket, his salary slip of 1.000 pounds per month (for a factory job of $60 \mathrm{~h}$ a week), and the various items he had bought with this money in London: a laptop, a mobile phone, cosmetics, clothes, gifts for his family. The scene revealed Sohang's desperation to return to India ("My ticket! See properly. It's a one-way ticket!") as well as the independence and status he had gained by going to London ("That's the shaving-machine. ... My father is gonna be really happy because he has never seen this before. I have to show him how to use it, he doesn't know.") His feelings of ambivalence became central elements both in the film and in the short stories Rutten wrote about Sohang $(2008,2009)$.

In a second editing round, we worked "from small to large". In this phase, a theme guided the editing. The process started with a scene we had identified as central, which was now reshaped by deleting distracting elements while adding additional footage to strengthen the thematic narrative. For example, the three-hour timeline of Sohang was reduced (by Verstappen) to a short story of approximately 20 min. The revised timeline focussed on Sohang's doubts about staying or going, and alternated between cheerful and sad moments to highlight his mixed feelings and insecurity. In it, Sohang left London, moved back to his hometown in Gujarat but was disappointed, reappeared in London, and then returned to India again in the hope of moving onwards to the USA. The footage in which Sohang talked about various other aspects of his life were left out in order to focus on the "stay or go" narrative.

A similar strategy was followed for the other protagonists - "from large to small" (a process of selection), then a discussion of key themes, and then "from small to large" (a process of synthesis). Reduction of complexity was an inevitable aspect of this procedure. While different migration motivations appeared in the narratives, we mostly focussed on one particular motive for each protagonist. Rather than describing one individual in his or her full complexity, the protagonists were thus reduced to (somewhat flat) characters. For example, Sohang was portrayed primarily as an 
economic migrant who had moved to London in the hope of obtaining money; another protagonist (Vishal) as an experience-seeker who came "to learn and to earn"; and the love story of a young couple in the house showed that love could also be a motive for migration. While this narrative strategy reduced complex individuals to the protagonist of a "migrant" (Trencsényi and Naumescu, Chap. 7, in this volume), the film still revealed diversity and complexity by exposing, through the different characters, a range of migration motivations.

The stories of the film characters were interwoven with dream sequences conveying aspirations, in the form of video-clips. The protagonists often spoke about their prior dreams of going to the West, and vice versa about their dreams of going back to India to escape the harsh realities of their life and work in London. Through video clips we could create dreamy sequences on both sides of the ocean, which became a counterpoint to the observational moments of the film in which their daily routines were followed. Although the choice of video clips can be seen as a break with earlier traditions of Observational Cinema that tended to refrain from adding external music layers, these clips stayed within the life worlds of the protagonists, using the favourite songs they themselves had posted on their social media (Orkut) pages.

Overall, the argument was inferred from a hybrid process involving both visual and textual modes of communication: filming, film editing, as well as writing and discussion. In the preparation phase, previous long-term research of a writing ethnographer (Rutten) informed the conceptualisation of the film. In this phase, we were guided by theories of transnationalism and migration studies, but also realised that the cohort of migrants we were filming did not neatly fit existing frameworks. During the filming phase, when open-ended conversations and observations were conducted, the team probed deeper into these issues of migration and transnationalism but was also drawn towards unforeseen themes, particularly towards the observable and practical aspects of the migration experience. In the editing phase, a process of reviewing, categorising, selecting, and connecting turned diverse and multilayered footages into a film - a process that resonates with established procedures of qualitative analysis that are normally advised for textual resources (cf. Bernhard \& Ryan, 2010; Boeije, 2005).

Our argument was not developed through one single medium. Rather than treating film and text as separate or radically different, we continually worked across both mediums to explore, reflect, discuss, and analyse migration experiences and motivations. Film drew our attention to the migrant's concrete everyday living experiences, in particular, to the simultaneous experiences of downward mobility in London and upward mobility in India. Writing enabled us to make our ideas explicit, to sharpen our internal discussions, and to publish about preliminary findings while the editing was still ongoing. In the end we all agreed on what we wanted to say, and on how we wanted to convey that story. When the films' protagonists saw the film and gave it their blessing, we knew that we got it right. 


\subsection{Teaching Ethnocinematographic Theory}

Teaching ethnocinematographic theory can be a challenge. While students enter universities with a range of visual communication skills, they tend to quickly learn that film is irrelevant within the academic world. They learn to regard film as mere time pass, as a resource to be studied, or as an illustrative teaching tool, not as a central conduit of theory formation. This has impact on their self-perception. Some students think clearly, are well-equipped to present their ideas orally in a classroom discussion, or have a natural talent for editing film to express their views, however, despite these cognitive talents, such students may come to believe they are not "theoretical" because they have learnt that only thoughts that are expressed through writing count as such. University lecturers have the option to break with this tradition. Below, I give practical advice to lecturers who wish to encourage their students to think from film. Even students with prior filmmaking training and advanced technological skills need this kind of academic support and supervision in order to discover how they can work with filmmaking practices during research.

\subsubsection{Step 1 - Treat Film and Text as Equal}

It is the task of any university lecturer to familiarise students with the two basic processes of theory formation - deduction (testing existing theory) and induction (developing new theory through ethnography), and then to make them aware when and how they are doing it (through process feedback). The first step towards enabling ethnocinematographic theory is to recognise that these processes of theory formation can develop across different platforms. If students learnt to associate "theory" with books and articles, they can also unlearn this association - if the lecturer enables them to think of film as an intellectual contribution to a discussion about how to see and understand the world, and of theory formation as a heuristic process that can evolve across different modes of expression. For example, lecturers can design systems of examination and evaluation in such a way that they treat the skills of montage, writing, and discussion as different and supplementary but equally important pathways to knowledge.

\subsubsection{Step 2 - Recognize the Analytical Potential of the Editing Room}

Within ethnographic filmmaking, the editing room is where filmmakers familiarize themselves with their footage and find linkages and contradictions within the material. It is through these practices of selection and synthesis that they start analysing their materials and develop an argument. Preliminary screenings and discussions of 
initial edits can help to clarify the argument; in the end, the editing is directed towards effectively expressing this argument. When these processes are recognized as analogous with processes of qualitative data analysis in the social sciences, so that students will be able to implement their acquired skills in later (even nonvisual) research projects, this can enhance their capacity not only as filmmakers but also as researchers.

\subsubsection{Step 3 - Stimulate Collective Genius}

While students work on a film project individually in some of my courses, I have often established film crews of 2-3 students, who bring a variety of talents, skills, and learning styles to their project. Collaboration encourages them to step out of their comfort zone and to learn about different ways of working beyond those they are familiar with. Contrary to practices in documentary film schools, I encourage students to form non-hierarchical crews of directors, to work in egalitarian relations with other students. This can create friction and discussion, which slows down the process, but enhances learning if students feel challenged to think critically about their initial interpretations of the footage, and to consider alternative interpretations and explanations. In the classroom, I stimulate discussions about these differences through break-away sessions and peer-to-peer meetings that encourage reflection on how interpretations are shaped by their own positions and experiences.

\subsection{Conclusion}

This chapter has shown how a film project about the migration of young people from middle class family backgrounds in India to London has produced a middlerange theory of "middling migration", which conceives of migration as an ambivalent experience of simultaneous downward and upward social mobility. This middle-range theory was first conceived through cinematographic means, through an observational style of cinema that shows how migrants move around in both India and London, and through a translocal montage of juxtaposition that draws connections and shows the differences between the two worlds. I have written this chapter to clarify how this analysis developed, collaboratively, while working across both text and film.

In this project, film was the central steering wheel: filmmaking was a way of learning about a new and unknown phenomenon. The analysis emerged from discussions of the footage as well as written field notes and short stories, and was developed through recording/editing plans and preliminary edits that were reviewed and discussed within the team. The resulting argument was conveyed cinematographically in the film, and made explicit in the article "Middling migration" to communicate with migration scholars. Following scholarly conventions, it was the 
article that was recognised and cited as an academic intervention in migration scholarship. The film was used in courses and events on migration and globalisation, and it was the first entry even for many academic colleagues to learn about the project; but it was the article that enabled our idea to be cited in migration studies. The combination of film and text thus enabled us to communicate about our idea to both academic and wider audiences.

For migration scholars who wish to use filmmaking as a research tool, an important benefit is the possibility to link and compare observations of situations in the "here" and the "there" through translocal montage. Other migration scholars, too, have filmed return trips of migrants to their country of origin, and have found that filming has helped them not merely to observe, but also to conceptualize transnational migration experiences (Torresan, 2011). The contribution of Living like a common man to the field of migration studies stems from its empirically grounded commitment to middle-range theorizing - the film draws on close observations of transnational migration experiences, and uses montage to constitute an audio-visual argument about how to interpret these experiences. Regarding visual anthropology, I have described why I treat observation and theory as connected, and text and film as supplementary modes of both observing and theorizing. This practical approach presents a challenge to polemic debates about the role of theory in ethnographic film that presuppose a binary distinction between "observational" film and "theoretical" texts; or between "descriptive" observational cinema versus "theoretically ambitious" montage films.

Acknowledgement The sections "How we developed ideas collaboratively" and "How we developed an argument through montage", which I wrote several years ago, were read by and received comments from both co-directors, Prof. Mario Rutten and Isabelle Makay (in 2014). After Mario's untimely death in 2015 I gave up the idea of publishing this article - I missed him, and it became painful to write about our collaboration. I thank the editors of this book for giving me a reason to publish it now.

\section{References}

Ahmad, A. N. (2011). Masculinity, sexuality and illegal migration: Human smuggling from Pakistan to Europe. Surrey, Canada: Ashgate.

Ali, S. (2007). "Go west young man": The culture of migration among Muslims in Hyderabad, India. Journal of Ethnic and Migration Studies, 33(1), 37-58.

Baas, M. (2010). Imagined mobility: Migration and transnationalism among Indian students in Australia. London/New York: Anthem Press.

Barbash, I., \& Taylor, L. (1997). Cross-cultural filmmaking: A handbook for making documentary and ethnographic film and videos. Berkeley, CA/Los Angeles/London: University of California Press.

Bernhard, H. R., \& Ryan, G. R. (2010). Analyzing qualitative data: Systematic approaches. Thousand Oaks, CA: Sage.

Beuving, J., \& de Vries, G. (2015). Theorizing society. In J. Beuving \& G. de Vries (Eds.), Doing qualitative research: The craft of naturalistic inquiry (pp. 47-63). Amsterdam: Amsterdam University Press. 
Bielewska, A. (2018). Game of labels: Identification of highly skilled migrants. Identities: Global Studies in Culture and Power, Published Online.

Boeije, H. (2005). Methoden en technieken van kwalitatieve analyse. In H. Boeije (Ed.), Analyseren in kwalitatief onderzoek: Denken en doen (p. 84-120). Den Haag: Boom Onderwijs.

Bryman, A. (2016). Social research methods (5th ed.). Oxford, UK: Oxford University Press.

Carta, S. (2014). Contribution to 'Where is the theory in visual anthropology?'. Visual Anthropology, 27(5), 452-454.

Choy, T. K., Faier, L., Hathaway, M. J., Inoue, M., Satsuka, S., \& Tsing, A. (2009). A new form of collaboration in cultural anthropology: Matsutake worlds. American Ethnologist, 36(2), 380-403.

Conradson, D., \& Latham, A. (2005a). Transnational urbanism: Attending to everyday practices and mobilities. Journal of Ethnic and Migration Studies, 31(2), 227-233.

Conradson, D., \& Latham, A. (2005b). Friendship, networks and transnationality in a world city: Antipodean transmigrants in London. Journal of Ethnic and Migration Studies, 31(2), 287-305.

da Col, G., \& Graeber, D. (2011). Foreword: The return of ethnographic theory. HAU: Journal of Ethnographic Theory, 1(1), vi-xxxv.

Glaser, B. G., \& Strauss, A. L. (1967). The discovery of grounded theory. Chicago: Aldine.

Helleiner, J. (2017). Recruiting the "culturally compatible" migrant: Irish working holiday migration and white settler Canadianness. Ethnicities, 17(3), 299-319.

Hockings, P. (2014). Contribution to 'Where is the theory in visual anthropology?'. Visual Anthropology, 27(5), 436-440.

Hockings, P., Tomaselli, K. G., Ruby, J., MacDougall, D., Williams, D., Piette, A., et al. (2014). Where is the theory in visual anthropology? Visual Anthropology, 27(5), 436-456.

Jankowski, K. Z. (2018). The middling mobile: Finding place in the Liquid City. Mobilities, 13(4), 601-614.

Jaskulowski, K. (2018). Indian middling migrants in Wrocbaw: A study of migration experiences and strategies. Asian and Pacific Migration Journal, 26(2), 262-273.

Kiener, W. (2008). The absent and the cut. Visual Anthropology, 21(5), 393-409.

Kirk, K., Bal, E., \& Janssen, S. R. (2017). Migrants in liminal time and space: An exploration of the experiences of highly skilled Indian bachelors in Amsterdam. Journal of Ethnic and Migration Studies, 43(16), 2771-2787.

Levin, C. M., \& Cruz, A. R. (2008). Behind the scenes of a visual ethnography: A dialogue between anthropology and film. Journal of Film and Video, 60(2), 59-68.

Lewis, E. D. (2004). Timothy Asch and ethnographic film. London/New York: Routledge.

Luthra, R., \& Platt, L. (2016). Elite or middling?: International students and migrant diversification. Ethnicities, 16(2), 316-344.

MacDougall, D. (2006). The corporeal image: Film, ethnography, and the senses. Princeton, NJ/ Oxford, UK: Princeton University Press.

MacDougall, D. (2008). Renewing ethnographic film: Is digital video changing the genre? Anthropology Today, 17(3), 15-21.

Mahi Tahi. (2018). An open letter to the HAU Journal's Board of Trustees. Website of the Association of Social Anthropologists of Aotearoa/New Zealand, June 18.

Mead, M. (2003). Visual anthropology in a discipline of words. In P. Hockings (Ed.), Principles of visual anthropology (pp. 3-10). Berlin, Germany/New York: Mouton de Gruyter.

Miller, S. I., \& Fredericks, M. (1999). How does grounded theory explain? Qualitative Health Research, 9(4), 538-551.

Postma, M., \& Crawford, P. I. (2006). Introduction: Visual etnography and anthropology. In M. Postma \& P. I. Crawford (Eds.), Reflecting visual ethnography: Using the camera in anthropological research (pp. 1-25). Leiden/Højbjerg: CNWS Publications/Intervention Press.

Ruby, J. (1995). Out of sync: The cinema of Tim Asch. Visual Anthropology Review, 11(1), 19-37.

Ruby, J. (2000). Picturing culture: Explorations of film \& anthropology. Chicago/London: The University of Chicago Press. 
Ruby, J. (2014). Contribution to 'Where is the theory in visual anthropology?'. Visual Anthropology, $27(5), 436-440$.

Rutten, M. (2008). Sohang (1). CUL: Antropologisch Verantwoord, 16(2), 22-23.

Rutten, M. (2009). Sohang (2). CUL: Antropologisch Verantwoord, 16(3), 29-19.

Rutten, M. (2015). Antropologische Ontmoetingen. Diemen, The Netherlands: AMB.

Rutten, M., \& Verstappen, S. (2014). Middling migration: Contradictory mobility experiences of Indian youth in London. Journal of Ethnic and Migration Studies, 40(8), 1217-1235.

Rutten, M., \& Verstappen, S. (2015). Reflections on migration through film: Screening of an anthropological documentary on Indian youth in London. Visual Anthropology, 28(5), 398-421.

Smith, M. P., \& Guarnizo, L. E. (Eds.). (1998). Transnationalism from below. Comparative urban and community research. New Brunswick: Transaction.

Suhr, C., \& Willerslev, R. (2012). Can film show the invisible?: The work of montage in ethnographic filmmaking. Current Anthropology, 53(3), 282-301.

Suhr, C., \& Willerslev, R. (2013). Transcultural Montage. Oxford, UK: Berghahn.

Torresan, A. (2011). Round trip: Filming a return home. Visual Anthropology Review, 27(2), $119-130$.

Upadhya, C. (2008). Management of culture and managing through culture in the Indian software outsourcing industry. In C. Upadhya \& A. R. Vasavi (Eds.), In an outpost of the global economy: Work and workers in India's information technology industry (pp. 101-135). New Delhi: Routledge.

van der Port, M. (2018). In love with my footage: Desirous undercurrents in the making of an essay film on Candomblé. Visual Anthropology Review, 34(2), 136-146.

Verstappen, S., Rutten, M., \& Makay, I. (2011). Living like a common man. University of Amsterdam, 65 minutes.

Xiang, B. (2007). Global 'body shopping': An Indian labour system in the information technology industry. Princeton, NJ: Princeton University Press.

Open Access This chapter is licensed under the terms of the Creative Commons Attribution 4.0 International License (http://creativecommons.org/licenses/by/4.0/), which permits use, sharing, adaptation, distribution and reproduction in any medium or format, as long as you give appropriate credit to the original author(s) and the source, provide a link to the Creative Commons license and indicate if changes were made.

The images or other third party material in this chapter are included in the chapter's Creative Commons license, unless indicated otherwise in a credit line to the material. If material is not included in the chapter's Creative Commons license and your intended use is not permitted by statutory regulation or exceeds the permitted use, you will need to obtain permission directly from the copyright holder. 